\title{
Influence of Area-Level Characteristics on the Suicide Rate in Korean Adolescents
}

\author{
Jungeun Song ${ }^{1 \star}$, Seongjun Park ${ }^{2 \star}$, Kangwoo Lee ${ }^{3}$, and Hyun Ju Hong ${ }^{3,4 凶}$ \\ ${ }^{1}$ Department of Psychiatry, National Health Insurance Service Ilsan Hospital, Goyang, Republic of Korea \\ ${ }^{2}$ Department of Social Welfare, University of Seoul, Seoul, Republic of Korea \\ ${ }^{3}$ Suicide and School Mental Health Institute, Anyang, Republic of Korea \\ ${ }^{4}$ Department of Psychiatry, Hallym University Sacred Heart Hospital, Anyang, Republic of Korea
}

\begin{abstract}
Objective We aimed to investigate the influence of area-level factors on adolescent suicide and to determine which variables differ according to age and sex.

Methods We selected variables that were available for collection through an online database from 2005 to 2015 in the Korean Statistical Information Service and the Korea Labor Institute. We used administrative districts of Korea in 2017 for geographical classification. We examined the relationships between regional suicide rates and area-level variables in male and female subjects aged 10-14 years and 15-19 years. In addition, we analyzed area-level variables in adolescents aged 15-19 years according to sex.

Results Our findings indicated that several area-level variables affected adolescent suicide rates, varying according to age and sex. Economic problems were shown to be more associated with suicide in male adolescents than in female adolescents. On the other hand, social fragmentation and health services were shown to be more associated with suicide in females.

Conclusion Suicide in adolescents was attributable to area-level factors such as economic status, social fragmentation, and community health services. By identifying area-level variables affecting adolescent suicide rates, we will be able to contribute to implement mental health policies related to adolescent suicide.

Psychiatry Investig 2019;16(11):800-807
\end{abstract}

Key Words Suicide, Area-level, Adolescent.

\section{INTRODUCTION}

Adolescent suicide is an important social issue and is emerging as a major public health problem around the world. ${ }^{1}$ This is no exception in Korea, where suicide is the leading cause of death in adolescents. ${ }^{2}$ Studies investigating the causes of adolescent suicide have examined various aspects of this issue. According to these studies, the factors influencing the adolescent suicide rate include individual-level factors such as the individual's psychopathology or experience of adverse life events, ${ }^{3-5}$ family factors such as a parent's mood disorder or

Received: January 23, 2019 Revised: April 23, 2019

Accepted: August 6, 2019

$\triangle$ Correspondence: Hyun Ju Hong, MD, PhD

Departmentof Psychiatry, Hallym University Sacred Heart Hospital, 22 Gwanpyeong-ro 170 beon-gil, Dongan-gu, Anyang 14068, Republic of Korea Tel: +82-31-380-3750, Fax: +82-31-380-4118, E-mail: honghj88@gmail.com

*These authors contributed equally to this work.

(a) This is an Open Access article distributed under the terms of the Creative Commons Attribution Non-Commercial License (https://creativecommons.org/licenses/by$\mathrm{nc} / 4.0$ ) which permits unrestricted non-commercial use, distribution, and reproduction in any medium, provided the original work is properly cited. abuse of the child, ${ }^{6}$ school factors such as bullying ${ }^{7}$ and arealevel factors such as markers of social fragmentation or deprivation..$^{8-10}$ Although area-level factors do not directly influence the suicide rate as much as individual factors, they do interact with other factors and significantly affect the suicide rate in adolescents. ${ }^{11}$

Adolescents grow up under the influence of the area in which they live. May and Jencks ${ }^{12}$ reviewed researches on how the neighborhood affects adolescents. Their report indicated that the characteristics of the neighborhood can influence adolescents by supervision or monitoring like parents do. According to another model, the contagion model, adolescents who are raised in low-socioeconomic-status neighborhoods may have more behavior problems than those raised in higher-socioeconomic-status neighborhoods, regardless of their family backgrounds. Adolescents are also affected by differences in local facilities such as parks, libraries and medical institutions. Based on these observations, it can be inferred that the mental health and suicide rates of adolescents are also influenced by the characteristics of the area in which they live. 
Several studies have explored the effects of area-level factors on individuals' mental health and the suicide rate. According to these studies, socioeconomic and environmental variables such as employment and social capital affect individuals' mental health. ${ }^{13}$ In another study about mental health differences among areas, there were more mental health problems in rural areas than in affluent areas, indicating that area-level characteristics can impact an individual's mental health. ${ }^{14}$ In a review article examining neighborhood risk factors affecting adolescents' mental health, neighborhood poverty, poor living conditions, violence and victimization were associated with common mental diseases in adolescents. ${ }^{15}$ In studies investigating area-level factors associated with suicide rates, the suicide rate was related to social fragmentation, ${ }^{16}$ income inequality, ${ }^{17}$ and poverty or deprivation. ${ }^{18}$

The risk factors and clinical characteristics of suicide are known to differ according to sex and age. Suicide in children aged 10-14 is rare, but the suicide rate increases rapidly after age $15 .{ }^{8}$ Psychopathology was found to be more frequent in older than in younger adolescents, and parent-child conflict was more common among younger suicide. ${ }^{19}$ The clinical characteristics of adolescent suicide also differ between male and female adolescents. Female adolescents tend to report more suicidal ideations and attempts and seek more help for mental health problems than male adolescents, while male adolescents complete suicide $3-4$ fold more. ${ }^{20}$ In a study analyzing the National Child Death Case Reporting System in the US, female adolescents who completed suicide were more likely to have mental health problems than male adolescents, but male adolescents were more likely to have substance abuse problems. ${ }^{21}$ In a study on area-level factors influencing the suicide rate, men were more affected than women by macro-societal factors such as female labor-force participation, an indicator of changes in gender roles and population-level fertility. ${ }^{22}$

These findings suggest that adolescent suicide risk is related to not only individual-level characteristics, but also arealevel characteristics based on where the adolescents live, and that these characteristics could vary according to age and sex. However, as far as we know, studies investigating the causes of adolescent suicide have mainly focused on individual-level rather than area-level perspectives. Thus, we aimed to investigate the influence of area-level factors on adolescent suicide and to determine which variables differ according to age and sex.

\section{METHODS}

\section{Data source and area-level variables}

We selected variables that could be collected through an online database among the various area-level factors associated with suicide. The regional suicide rates of adolescents and most of the area-level variables from 2005 to 2015 were obtained from the Korean Statistical Information Service, ${ }^{2}$ and the relative poverty rate was obtained from the Korea Labor Institute. ${ }^{23}$ The area-level variables included the sex ratio, population density, aging index, population inflow, gross regional domestic product (GRDP) per capita, employment rates for those from 15 to 64 years of age, rate of social welfare expenditure in general accounts, rate of married foreign women, number of crimes per 1,000, one-person household rate and number of psychiatrists per 100,000. Gross regional domestic product (GRDP) is the total value of produced goods and services in a certain area in a certain period of time and GRDP per capita is GRDP divided by the number of people living there. It is associated with the level of wealth of the people in the region. Rate of social welfare expenditure is the proportion of social welfare expenditure of the gross budget in the region. The relative poverty rate is the proportion of people whose income falls below $50 \%$ in order of income levels. The relative poverty rates in the region were calculated with Korean Labor \& Income Panel Study data from the Korea Labor Institute. ${ }^{23}$ It should be noted that the number of households sampled in Jeju Island in the Korean Labor \& Income Panel Study was insufficient before 2008 , so the relative poverty rates of Jeju Island were calculated with data obtained after 2008. The detailed measurements of these variables are summarized in Table 1 . The population density and GRDP per capita were transformed to natural logarithm forms for further analysis, since these factors were positively skewed. The raw data are shown in Supplementary Table 1 (in the online-only Data Supplement). Our study was approved by the Institutional Review Board of Hallym University Sacred Heart Hospital (IRB approval number; Hallym 2018-04-002).

\section{Geographical classification}

We used the administrative districts of Korea in 2017 for geographical classification. There were 17 local governments (8 metropolitan cities and 9 provinces) in Korea as of 2017. Metropolitan cities usually have a population of one million and a high population density. Provinces include small cities and the country, and have a low population density. Sejong City, which was newly established in 2012, was excluded from the analysis, since no regional statistics on suicide rates in the city were available. Thus, we analyzed data of 7 metropolitan cities and 9 provinces.

\section{Analysis}

In this study, a panel data model using Generalized Least Squares (GLS) was constructed to investigate the area-level factors affecting the regional suicide rates of adolescents in South Korea. Panel data models account for unobserved het- 
Table 1. Definitions and sources of the area-level variables

\begin{tabular}{|c|c|c|}
\hline Variables & Calculation of variables & Source \\
\hline $\begin{array}{l}\text { Suicide rates among young people } \\
\text { aged } 10^{-14} \text { and } 15^{-19}\end{array}$ & $\begin{array}{l}\text { (Number of deaths caused by intentional self-harm in a region } \div \text { Regional } \\
\text { population }) \times 100,000\end{array}$ & Statistics Korea \\
\hline Sex ratio & (Number of men $\div$ Number of women $) \times 100$ & Statistics Korea \\
\hline Population density & Regional population $\div$ Size of regional area $\left(\mathrm{km}^{2}\right)$ & Statistics Korea \\
\hline Aging index & (Number of people over $65 \div$ Number of people under 15$) \times 100$ & Statistics Korea \\
\hline Population inflow & (Number of people who moved in-Number of people who moved out) $\div 1,000$ & Statistics Korea \\
\hline Relative poverty rate & $\begin{array}{l}\text { (Number of households below } 50 \% \text { of the national median income } \div \\
\text { Total number of households in the region) } \times 100\end{array}$ & Korea labor institute \\
\hline GRDP per capita (million Won) & Gross regional domestic product (million Won) $\div$ Regional population & Statistics Korea \\
\hline Employment rate of those aged 15-64 & (Number of employees aged $15-64 \div$ Number of people aged $15-64) \times 100$ & Statistics Korea \\
\hline $\begin{array}{l}\text { Rate of social welfare expenditure } \\
\text { in general accounts }\end{array}$ & (Social welfare expenditure $\div$ Gross budget $) \times 100$ & Statistics Korea \\
\hline Divorce rate of women $(\%)$ & $\begin{array}{l}\text { (Number of divorced women aged } \geq 15 \div \text { Mid-year population of women } \\
\text { aged } \geq 15) \times 1,000\end{array}$ & Statistics Korea \\
\hline Rate of married foreign women $(\%)$ & $\begin{array}{l}\text { (Number of foreign women married to men including Koreans and foreigners:- } \\
\text { Number of married women }) \times 1,000\end{array}$ & Statistics Korea \\
\hline Number of crimes per 1,000 & (Number of crimes in the region $\div$ Regional population $) \times 1,000$ & Statistics Korea \\
\hline One-person household rate & $\begin{array}{l}\text { (Number of one-person households } \div \text { Total number of households in the region) } \\
\times 100\end{array}$ & Statistics Korea \\
\hline Number of psychiatrists per 100,000 & $\begin{array}{l}\text { (Number of psychiatrists in the region } \div \text { Number of people aged } 10-19 \\
\text { in the region) } \times 100,000\end{array}$ & Statistics Korea \\
\hline
\end{tabular}

GRDP: Gross Regional Domestic Product

eroskedasticity and autocorrelation on each observation over time. ${ }^{24}$ Additionally, panel data models can obtain more efficient estimates than cross-sectional data because panel data models use more information. The Stata13.1 (StataCorp LP, College Station, TX, USA ${ }^{25}$ statistical package was used for panel data analysis. We used a modified Wald test for groupwise heteroskedasticity and a Wooldridge test for autocorrelation for the panel data in the Stata package.

We conducted t-test to analyze the difference in suicide rates between age 10-14 and 15-19. In addition, we compared suicide rate by sex in each age group. We examined the relationship between the regional suicide rate and area-level variables in 10-14 year-olds in Model 1 and 15-19 year-olds in Model 2. Finally, we analyzed the area-level variables in adolescents aged 15-19 years according to sex in Models 3 and 4 .

\section{RESULTS}

\section{Descriptive data on regional adolescent suicide rates and area-level variables}

The descriptive statistical results for the regional suicide rates among adolescents and the area-level variables are shown in Table 2. The mean number of adolescents aged 10 to 14 who committed suicide per 100,000 from 2005 to 2015 was 1.41 in South Korea. The mean number of adolescents aged 15 to
19 who committed suicide per 100,000 was 8.19 . There were more men than women in the average population of South Korea from 2005 to 2015 . The average population per square kilometer was 2,311 from 2005 to 2015. The average aging index in South Korea was 76.27, with a maximum value of 165.00 and a minimum value of 23.60. The average number of people who moved out was about 610 ; the maximum value of people who moved in was 168.85 thousand, and the maximum value of people who moved out was 137.26 thousand from 2005 to 2015 . The percentage of relative poverty (below 50\% of the national median income) in 16 regions was $26 \%$ from 2005 to 2015 on average. The average GRDP per capita was 25.72 million Won in South Korea. The average employment rate of Koreans aged 15-64 was 64.08\% from 2005 to 2015. The social welfare expenditure of the Korean government was $24.46 \%$ of the gross budget. The divorce rate of women over the age of 15 was $5.23 \%$, and the rate of married foreign women in South Korea was 7.80\%o from 2005 to 2015 on average. The average number of crime cases per thousand persons was 36.53 . One-person households comprised $24.48 \%$ of the total number of households. The average number of psychiatrists per 100,000 persons was 38.78 from 2005 to 2015.

The regional suicide rates by sex among young people aged 10-14 and 15-19 for 7 metropolitan cities (M) and 9 provinc- 
es $(\mathrm{P})$ are shown in Table 3. The regional suicide rate of adolescents aged 10-14 was lower than the regional suicide rate of those aged $15-19(\mathrm{p}=0.000)$. There was no difference in the suicide rate by sex in the aged $10-14$ group $(\mathrm{p}=0.925)$. While the regional suicide rate of adolescents aged 15-19 tended to be higher for male adolescents than for female adolescents $(\mathrm{p}=0.001)$.

\section{Association of regional adolescent suicide rates with area-level factors}

In Model 1, we analyzed the relationship between the regional suicide rate and area-level variables in 10-14 year-olds. There were no significant area-level variables except for the number of crimes per thousand. In Model 2, analyzing 1519 year-olds, the population density $(\mathrm{p}=0.039)$, population inflow $(\mathrm{p}=0.001)$, relative poverty rate $(\mathrm{p}=0.000)$, GRDP per capita $(\mathrm{p}=0.000)$, employment rate of those aged $15-64(\mathrm{p}=$ $0.000)$, rate of married foreign women $(\mathrm{p}=0.000)$, number of crimes $(\mathrm{p}=0.000)$ and number of psychiatrists per 100,000 persons ( $\mathrm{p}=0.015)$ were statistically significant (Table 4$)$.

We analyzed the area-level variables in adolescents aged 15-19 years according to sex in Models 3 and 4. The area-level variables differentially influenced the regional suicide rate according to sex. For male suicides, the population inflow $(\mathrm{p}=$ $0.000)$, relative poverty rate $(\mathrm{p}=0.001)$, GRDP per capita $(\mathrm{p}=$ $0.000)$, employment rate of those aged $15-64(\mathrm{p}=0.002)$, rate of social welfare expenditure in general accounts $(\mathrm{p}=0.004)$, rate of married foreign women $(\mathrm{p}=0.014)$ and number of crimes per thousand $(\mathrm{p}=0.000)$ significantly affected the suicide rate. Whereas for female suicides, the population density $(\mathrm{p}=0.001)$, population inflow $(\mathrm{p}=0.007)$, relative poverty rate $(\mathrm{p}=0.006)$, number of crimes per $100,000(\mathrm{p}=0.005)$, one-person household rate $(\mathrm{p}=0.036)$ and number of psychiatrists $(\mathrm{p}=0.002)$ significantly influenced the regional suicide rate.

\section{DISCUSSION}

We examined the associations of area-level factors with re-

Table 2. Descriptive data on regional adolescent suicide rates and area-level variables from 2005 to 2015

\begin{tabular}{|c|c|c|c|c|}
\hline & Mean & SD & $\operatorname{Max}$ & Min \\
\hline Suicide rate among younger adolescents (aged 10-14) & 1.41 & 1.07 & 5.10 & 0.00 \\
\hline Suicide rate among older adolescents (aged 15-19) & 8.19 & 2.74 & 18.60 & 2.40 \\
\hline Sex ratio $(\%)$ & 100.94 & 2.85 & 108.70 & 95.90 \\
\hline Population density $\left(\mathrm{km}^{2}\right)$ & 2311.01 & 3988.48 & 16758.00 & 89.00 \\
\hline Aging index & 76.27 & 29.53 & 165.00 & 23.60 \\
\hline Population inflow (thousands) & -0.61 & 37.35 & 168.85 & -137.26 \\
\hline Relative poverty rate (\%) & 26.28 & 7.22 & 47.22 & 6.55 \\
\hline GRDP per capita (million Won) & 25.72 & 10.39 & 62.94 & 12.26 \\
\hline Employment rate of those aged 15-64 (\%) & 64.08 & 2.60 & 72.20 & 59.40 \\
\hline Rate of social welfare expenditure in general accounts & 24.46 & 7.95 & 42.69 & 9.08 \\
\hline Divorce rate of females (\%o) & 5.23 & .76 & 8.50 & 4.00 \\
\hline Rate of married foreign women (\%o) & 7.80 & 2.44 & 15.06 & 3.94 \\
\hline Number of crimes per thousand & 36.53 & 4.50 & 54.16 & 29.58 \\
\hline One-person household rate (\%) & 24.48 & 3.48 & 31.43 & 16.83 \\
\hline Number of psychiatrists per 100,000 & 38.78 & 10.42 & 67.27 & 15.55 \\
\hline
\end{tabular}

GRDP: Gross Regional Domestic Product

Table 3. Regional suicide rates among young people aged 10-14 and 15-19 (number of deaths caused by suicide per 100,000 people in a region)

\begin{tabular}{|c|c|c|c|c|c|c|c|c|c|c|c|c|c|c|c|c|c|c|}
\hline Region & M1 & M2 & M3 & M4 & M5 & M6 & M7 & $\mathrm{P} 1$ & $\mathrm{P} 2$ & P3 & $\mathrm{P} 4$ & P5 & P6 & P7 & P8 & P9 & $\mathrm{t}$ & $\mathrm{p}$ \\
\hline \multicolumn{19}{|c|}{ Suicide rate (10-14 years old) } \\
\hline Male & 1.23 & 2.15 & 1.02 & 1.59 & 1.07 & 1.31 & 1.10 & 1.46 & 2.00 & 1.72 & 1.25 & 1.12 & 1.23 & 1.32 & 1.48 & 1.29 & \multirow{2}{*}{\multicolumn{2}{|c|}{0.0940 .925}} \\
\hline Female & 1.29 & 1.83 & 1.14 & 2.14 & 2.00 & 1.15 & 0.89 & 1.74 & 1.43 & 0.93 & 1.90 & 0.76 & 1.11 & 1.37 & 1.76 & 1.54 & & \\
\hline \multicolumn{19}{|c|}{ Suicide rate (15-19 years old) } \\
\hline Male & 9.20 & 8.95 & 7.81 & 8.96 & 10.09 & 8.55 & 7.57 & 7.71 & 8.67 & 8.62 & 11.31 & 7.84 & 12.64 & 9.36 & 7.69 & 7.74 & \multirow{2}{*}{\multicolumn{2}{|c|}{3.3990 .001}} \\
\hline Female & 6.11 & 7.83 & 7.33 & 7.98 & 7.43 & 8.85 & 6.47 & 7.36 & 6.43 & 6.37 & 8.75 & 5.92 & 8.54 & 7.06 & 6.28 & 9.93 & & \\
\hline
\end{tabular}

M: metropolitan city, P: province 
Table 4. The effect of area-level variables on the suicide rates among young people in South Korea (by age, sex)

\begin{tabular}{|c|c|c|c|c|}
\hline & Model 1 & Model 2 & Model 3 & Model 4 \\
\hline & Suicide rate & Suicide rate & Suicide rate & Suicide rate \\
\hline & aged $10-14$ & aged $15-19$ & aged 15-19, male & aged $15-19$, female \\
\hline & \multicolumn{4}{|c|}{ Coefficient (standard error) } \\
\hline Year & $-0.024(0.072)$ & $0.173(0.173)$ & $-0.260(0.217)$ & $0.046(0.255)$ \\
\hline Sex ratio & $0.092(0.073)$ & $-0.067(0.155)$ & $-0.248(0.205)$ & $0.281(0.223)$ \\
\hline Population density $\left(\mathrm{km}^{2}, \ln \right)$ & $0.158(0.143)$ & $0.675(0.327)^{*}$ & $0.564(0.448)$ & $1.697(0.488)^{\dagger}$ \\
\hline Aging index & $0.011(0.009)$ & $-0.002(0.019)$ & $-0.004(0.026)$ & $0.030(0.028)$ \\
\hline Population inflow (thousands) & $0.003(0.002)$ & $0.015(0.005)^{\dagger}$ & $0.023(0.006)^{\ddagger}$ & $0.026(0.007)^{\ddagger}$ \\
\hline Relative poverty rate (\%) & $0.019(0.018)$ & $0.171(0.042)^{\ddagger}$ & $0.183(0.057)^{\dagger}$ & $0.176(0.064)^{\dagger}$ \\
\hline GRDP per capita (million Won, $\ln$ ) & $0.178(0.540)$ & $4.16(1.154)^{\ddagger}$ & $7.831(1.478)^{\ddagger}$ & $0.798(1.717)$ \\
\hline Employment rate of those aged 15-64 (\%) & $-0.042(0.040)$ & $-0.419(0.101)^{\ddagger}$ & $-0.394(0.126)^{\dagger}$ & $-0.244(0.128)$ \\
\hline Rate of social welfare expenditure in general accounts & $0.036(0.021)$ & $0.065(0.049)$ & $0.186(0.064)^{\dagger}$ & $-0.013(0.077)$ \\
\hline Divorce rate of females (\%o) & $0.167(0.164)$ & $-0.051(0.385)$ & $0.040(0.500)$ & $-0.039(0.520)$ \\
\hline Rate of married foreign women (\%o) & $0.082(0.066)$ & $0.530(0.150)^{\ddagger}$ & $0.458(0.186)^{*}$ & $0.164(0.208)$ \\
\hline Number of crimes per thousand & $0.040(0.016)^{*}$ & $0.144(0.035)^{\ddagger}$ & $0.196(0.048)^{\ddagger}$ & $0.157(0.057)^{\dagger}$ \\
\hline One-person household rate (\%) & $-0.018(0.073)$ & $0.129(0.138)$ & $0.209(0.207)$ & $0.449(0.215)^{*}$ \\
\hline Number of psychiatrists per 100,000 & $0.001(0.017)$ & $-0.094(0.039)^{*}$ & $-0.076(0.051)$ & $-0.171(0.055)^{\dagger}$ \\
\hline Intercept & $-11.263(8.067)$ & $7.91(18.509)$ & $11.493(24.748)$ & $-37.434(24.696)$ \\
\hline Wald chi-square test (df) & $2.39(14)$ & $102.97(14)^{\ddagger}$ & $101.71(14)^{\ddagger}$ & $49.75(14)^{\ddagger}$ \\
\hline Autocorrelation test (df) & $1.502(1,15)$ & $6.661(1,15)^{*}$ & $0.082(1,15)$ & $2.77(1,15)$ \\
\hline Heteroskedasticity test (df) & $1925.03(16)^{\ddagger}$ & $2068.44(16)^{\ddagger}$ & $19641.1(16)^{\ddagger}$ & $27.06(16)^{\ddagger}$ \\
\hline
\end{tabular}

${ }^{*} \mathrm{p}<0.05,{ }^{\dagger} \mathrm{p}<0.01,{ }^{\ddagger} \mathrm{p}<0.001$. GRDP: Gross Regional Domestic Product

gional suicide rates using data of Statistics Korea from 2005 to 2015 in South Korea. In particular, our study focused on the influence of area-level factors on suicide rates according to age and sex. Our results showed that suicide in adolescents were related to area-level factors such as economic status, social fragmentation, and availability of community health services and these factors were vary according to age and sex.

The impact of society on suicide was initially discussed in the work of Durkheim. ${ }^{26}$ According to Durkheim, society affects an individual's susceptibility to suicide, and the collective rate of suicide in any certain group reflects geographical, social, and economic characteristics in context. ${ }^{22}$ Suicide risk factors at a social level are not the simple summation of individual risk factors. Indeed, studies that focus on individual-level risk factors have limitations in investigating the fundamental causes of suicide and suicide prevention. ${ }^{27}$ Accordingly, the strength of our study is in its examination of factors influencing suicide in adolescents from a macro perspective.

Our findings indicated that several area-level variables affected adolescent suicide rates, varying according to age and sex. Area-level factors influencing adolescent suicide rates in our results could be classified into several categories. First, there was a factor pertaining to social relations-namely, the one-person household rate. Second, there were factors related to economic status including employment rate, GRDP per capita, and relative poverty rate. Third, related to community health services was the number of psychiatrists per population by region. Fourth, there were factors associated with urbanicity including population density and population inflow. Other area-level factors that are shown to influence adolescent suicide rates in our period of study were rate of social welfare expenditure in general accounts, rate of married foreign women, and number of crimes per thousand in population samples.

In adolescents aged 10-14 years, only the number of crimes per thousand influenced the suicide rate. We postulated that only one variable was associated with the suicide rate in this group because the suicide rate was much lower in this group than in adolescents aged 15-19 years. That is, it was not possible to obtain statistically significant results for other variables due to the small sample size of suicides in the group of subjects aged $10-14$ years. On the other hand, our findings suggested that suicide rate in adolescents under the age of 15 was less influenced by area-level factors. Our results differed slightly from the results of previous studies investigating suicidal behavior and crime in a community. In previous reports, 
objective levels of violent crime in a neighborhood were not associated with psychological distress ${ }^{28}$ or suicidal behavior in adolescents. ${ }^{29}$ According to these previous studies, the subjective perception of neighborhood crime is more important than objective levels of violence. Our study investigated only the objective crime rate; thus, our results did not exactly agree with previous findings.

Our results demonstrated that variables including social relations, economic status, and health services influenced suicide rates in the group of subjects aged 15-19 years. When we compared the results of male and female suicides, we found that the GRDP per capita, employment rates in people aged 15-64 years, rate of social welfare expenditure in general accounts, and rate of married foreign women were associated with suicide rate in males, but not in females. In previous studies, male suicide rates have been shown to be associated with unemployment ${ }^{30}$ and with female labor-force participation. ${ }^{22}$ Previous research has surmised that unemployment was considered to be a more fatal suicide risk factor for males than for females, because jobs were more a source of self-worth for males. ${ }^{31}$ Our study suggested that this phenomenon applies not only to adults, but also to adolescents. In our results, the relative poverty rate was shown to influence suicide rates in both male and female adolescents. This result was compatible with the results of a previous study in which the relative poverty rate was shown to be associated with suicide risk, and wherein this association was strong for males. ${ }^{32}$ Our study also showed that GRDP per capita was negatively associated with suicide rate in male adolescents. It has been reported that gross domestic product (GDP) is related to suicide rates worldwide, with the direction differing according to country. ${ }^{33}$ In previous research, GDP and suicide rates have seemed to follow an inverted U-shaped curve, meaning that suicide trends decline after peaking at a certain point of economic development. ${ }^{34}$ Considering our results and the findings of other research, it could be postulated that high level of income inequality-despite economic development-was associated with suicide risk in Korean male adolescents. Another finding was that rate of social welfare expenditure in general accounts was positively associated with suicide rate in male adolescents aged 15-64 years. This might be because social welfare expenditure was largely set in areas housing a significant proportion of the socioeconomically vulnerable population.

Another finding in our study was that the rate of married foreign women influenced the suicide rate in male adolescents only. According to the study on multicultural families in Korea, only young males with foreign-born mothers had a greater suicide risk than non-multicultural boys. ${ }^{35}$ In a Norwegian study, immigrant boys had more anxiety and depression than young males of a domestic background, but no such differenc- es were observed among girls. ${ }^{36}$ Our results were consistent with these findings. There are several possible reasons that potentially impact suicide rates in multicultural or immigrant families with male adolescents only. This sex difference may be because male adolescents are more sensitive to minority discrimination than female adolescents. Another reason may be that multicultural families are more likely to have a low economic status.

In female adolescents aged 15-19 years, we found that population density, one-person household rate, and number of psychiatrists per 100,000 people influenced suicide rates, while these variables did not influence male suicides. Female teenagers tend to be more socialized, relationship-oriented, and empathetic to family than male teenagers. ${ }^{37,38}$ Accordingly, female adolescents were expected to be more sensitive to factors pertaining to social relations. Therefore, family structure problems, such as family disorganization, need to be monitored constantly to manage regional suicide rates, particularly in female adolescents. The results of our study indicate that the number of psychiatrists per 100,000 people in a region had a negative effect on suicide rate in females aged $15-19$ years. In previous studies, differences were observed between male and female adolescents in help-seeking behaviors, and female adolescents were more likely than males to seek help. ${ }^{39,40}$ Female adolescents have also been shown to be more likely to visit doctors (especially general practitioners) or to contact emergency departments than males. ${ }^{40}$ These factors might contribute to the lower suicide rates in female adolescents than in male adolescents. ${ }^{20}$ Our results were consistent with these previous results. Our findings suggested that a sufficient number of mental health care facilities such as specialized hospitals, welfare institutions, and counseling facilities for adolescent suicide prevention should be established based on the population size of a region. In our findings, population density also had an influence on female suicide rates. This was consistent with the Ireland study in which high population density (urbanicity) was shown to be related to increased suicide rate in a group of females aged 15-39 years. ${ }^{41}$ Because urbanicity may differently influence males and females, urbanicity would be associated with high suicide rates only in females. That is, in urban settings, greater opportunities for employment most benefit men, while women might be vulnerable to this competitive environment. ${ }^{42}$ However, there was a limit to apply this postulation to adolescents and further study is needed.

There were some limitations to our study. First, even though individual-level and area-level variables interact with one another to influence suicide rates, ${ }^{43}$ we were not able to investigate this interaction. The effects of the community on suicide rates may be due to characteristics of the individuals who comprise the community (compositional effects) or due to 
factors in the community in which an individual lives. ${ }^{10}$ It seems plausible that area-level associations with suicide could be attenuated following adjustment for individual-level characteristics. We could not identify the area-level variables associated with suicide independent of individual variables. Second, our study was cross-sectional, not longitudinal; thus, we could not determine the causal relationship between suicide rates and area-level factors. Third, because we used an online database, the available variables were limited. Fourth, we did not consider potential interactions among area-level variables and therefore could not control for confounding factors.

The current research attributes suicide in adolescents to area-level factors such as economic status, social fragmentation, and availability of community health services. The influence of these variables on suicide rates was shown to vary according to age and sex. Based on the findings herein, we suggested that economic problems are more associated with suicide in male adolescents than in female adolescents. On the other hand, social fragmentation and health services are more associated with suicide in female adolescents. By identifying area-level variables affecting adolescent suicide rates, we will be able to contribute to implement mental health policies related to adolescent suicide. Longitudinal research is needed to analyze additional variables and the interactions between individuallevel and area-level factors.

\section{Supplementary Materials}

The online-only Data Supplement is available with this article at https://doi.org/10.30773/pi.2019.0025.

\section{Conflicts of Interest}

The authors have no potential conflicts of interest to disclose.

\section{Author Contributions}

Conceptualization: Jungeun Song, Seongjun Park, Kangwoo Lee, Hyun Ju Hong. Data curation: Seongjun Park. Formal analysis: Seongjun Park. Investigation: Jungeun Song. Methodology: Seongjun Park. Project administration: Hyun Ju Hong. Supervision: Hyun Ju Hong. Validation: Hyun Ju Hong. Visualization: Jungeun Song. Writing_-original draft: Jungeun Song. Writing-review and editing: Jungeun Song, Seongjun Park, Kangwoo Lee, Hyun Ju Hong.

\section{ORCID iDs}

Hyun Ju Hong https://orcid.org/0000-0002-6348-9996

Jungeun Song https://orcid.org/0000-0003-0697-9320

\section{REFERENCES}

1. Abraham ZK, Sher L. Adolescent suicide as a global public health issue. Int J Adolesc Med Health 2017;31(4).

2. Statistics Korea. Cause of Death Statistics. Available at: http://kosis.kr/ statisticsList/statisticsListIndex.do?menuId=M_01_01. Accessed December 1, 2017.

3. Lee D, Jung S, Park S, Hong HJ. The impact of psychological problems and adverse life events on suicidal ideation among adolescents using nationwide data of a school-based mental health screening test in Ko- rea. Eur Child Adolesc Psychiatry 2018;27:1361-1372.

4. Beautrais AL. Risk factors for suicide and attempted suicide among young people. Aust N Z J Psychiatry 2000;34:420-436.

5. Serafini G, Muzio C, Piccinini G, Flouri E, Ferrigno G, Pompili M, et al. Life adversities and suicidal behavior in young individuals: a systematic review. Eur Child Adolesc Psychiatry 2015;24:1423-1446.

6. Brent DA, Mann JJ. Familial pathways to suicidal behavior--understanding and preventing suicide among adolescents. N Engl J Med 2006;355: 2719-2721.

7. Holt MK, Vivolo-Kantor AM, Polanin JR, Holland KM, DeGue S, Matjasko JL, et al. Bullying and suicidal ideation and behaviors: a meta-analysis. Pediatrics 2015;135:e496-e509.

8. Hawton K, Saunders KE, O'Connor RC. Self-harm and suicide in adolescents. Lancet 2012;379:2373-2382.

9. Evans E, Hawton K, Rodham K. Factors associated with suicidal phenomena in adolescents: a systematic review of population-based studies. Clin Psychol Rev 2004;24:957-979.

10. Zammit S, Gunnell D, Lewis G, Leckie G, Dalman C, Allebeck P. Individual- and area-level influence on suicide risk: a multilevel longitudinal study of Swedish schoolchildren. Psychol Med 2014;44:267-277.

11. Bridge JA, Goldstein TR, Brent DA. Adolescent suicide and suicidal behavior. J Child Psychol Psychiatry 2006;47:372-394.

12. Mayer SE, Jencks C. Growing up in poor neighborhoods: how much does it matter? Science 1989;243:1441-1445.

13. Goetz SJ, Davlasheridze M, Han Y. Country-level determinants of mental health 2002-2008. Soc Indic Res 2015;124:657-670.

14. Fraser CE, Smith KB, Judd F, Humphreys JS, Fragar LJ, Henderson A. Farming and mental health problems and mental illness. Int J Soc Psychiatry 2005;51:340-349.

15. Curtis S, Pain R, Fuller S, Khatib Y, Rothon C, Stansfeld SA, et al. Neighbourhood risk factors for common mental disorders among young people aged 10-20 years: a structured review of quantitative research. Health Place 2013;20:81-90.

16. Whitley E, Gunnell D, Dorling D, Smith GD. Ecological study of social fragmentation, poverty, and suicide. BMJ 1999;319:1034-1037.

17. Miller JR, Piper TM, Ahern J, Tracy M, Tardiff KJ, Vlahov D, et al. Income inequality and risk of suicide in New York City neighborhoods: a multilevel case-control study. Suicide Life Threat Behav 2005;35:448-459.

18. Rehkopf DH, Buka SL. The association between suicide and the socioeconomic characteristics of geographical areas: a systematic review. Psychol Med 2006;36:145-157.

19. Brent DA, Baugher M, Bridge J, Chen T, Chiappetta L. Age- and sex-related risk factors for adolescent suicide. J Am Acad Child Adolesc Psychiatry 1999;38:1497-1505.

20. Beautrais AL. Gender issues in youth suicidal behaviour. Emerg Med (Fremantle) 2002;14:35-42.

21. Trigylidas TE, Reynolds EM, Teshome G, Dykstra HK, Lichenstein R. Paediatric suicide in the USA: analysis of the National Child Death Case Reporting System. Inj Prev 2016;22:268-273.

22. Milner A, McClure R, De Leo D. Socio-economic determinants of suicide: an ecological analysis of 35 countries. Soc Psychiatry Psychiatr Epidemiol 2012;47:19-27.

23. Korea Labor Institute. Korean Labor \& Income Panel Study. Available at: https://www.kli.re.kr/klips_eng/index.do. Accessed December 1, 2017.

24. Cameron AC, Trivedi PK. Microeconometrics Using Stata. TX: Stata press College Station; 2010.

25. StataCorp LP. Texas: College Station; 2013.

26. Durkheim E. Suicide: A Study in Sociology. New York: Free Press; 1997.

27. Maris RW. Social suicide. Suicide Life Threat Behav 1997;27:41-49.

28. Goldman-Mellor S, Margerison-Zilko C, Allen K, Cerda M. Perceived and objectively-measured neighborhood violence and adolescent psychological distress. J Urban Health 2016;93:758-769.

29. Allen K, Goldman-Mellor S. Neighborhood characteristics and adolescent suicidal behavior: evidence from a population-based study. Suicide 
Life Threat Behav 2018;48:677-689.

30. Breuer C. Unemployment and suicide mortality: evidence from regional panel data in Europe. Health Econ 2015;24:936-950.

31. Kuroki M. Suicide and unemployment in Japan: evidence from municipal level suicide rates and age-specific suicide rates. J Socio Econ 2010;39: 683-691.

32. Inoue K, Fujita Y, Takeshita H, Abe S, Fujihara J, Ezoe S, et al. A longterm study of the association between the relative poverty rate and suicide rate in Japan. J Forensic Sci 2016;61(Suppl 1):S140-S143.

33. Blasco-Fontecilla H, Perez-Rodriguez MM, Garcia-Nieto R, FernandezNavarro P, Galfalvy H, de Leon J, et al. Worldwide impact of economic cycles on suicide trends over 3 decades: differences according to level of development. A mixed effect model study. BMJ Open 2012;2.

34. Moniruzzaman S, Andersson R. Economic development as a determinant of injury mortality-a longitudinal approach. Soc Sci Med 2008;66: 1699-1708.

35. Bahk J, Kim AM, Khang YH. Associations of multicultural status with depressive mood and suicidality among Korean adolescents: the roles of parental country of birth and socioeconomic position. BMC Public Health 2017;17:116.

36. Oppedal B, Roysamb E. Mental health, life stress and social support among young Norwegian adolescents with immigrant and host national background. Scand J Psychol 2004;45:131-144.
37. Langhinrichsen-Rohling J, Friend J, Powell A. Adolescent suicide, gender, and culture: a rate and risk factor analysis. Aggr Viol Behav 2009; 14:402-414.

38. Kerr DC, Preuss LJ, King CA. Suicidal adolescents' social support from family and peers: gender-specific associations with psychopathology. J Abnorm Child Psychol 2006;34:99-110.

39. Bearman PS, Moody J. Suicide and friendships among American adolescents. Am J Public Health 2004;94:89-95.

40. Rhodes AE, Khan S, Boyle MH, Tonmyr L, Wekerle C, Goodman D, et al. Sex differences in suicides among children and youth: the potential impact of help-seeking behaviour. Can J Psychiatry 2013;58:274-282.

41. O'Farrell IB, Corcoran P, Perry IJ. The area level association between suicide, deprivation, social fragmentation and population density in the Republic of Ireland: a national study. Soc Psychiatry Psychiatr Epidemiol 2016;51:839-847.

42. Qin P, Agerbo E, Mortensen PB. Suicide risk in relation to socioeconomic, demographic, psychiatric, and familial factors: a national register-based study of all suicides in Denmark, 1981-1997. Am J Psychiatry 2003;160:765-772.

43. Burrows S, Auger N, Gamache P, St-Laurent D, Hamel D. Influence of social and material individual and area deprivation on suicide mortality among 2.7 million Canadians: a prospective study. BMC Public Health 2011;11:577. 
Supplementary Table 1. Community variables of seven metropolitan cities and nine provinces in Korea from 2005 to 2015

\begin{tabular}{|c|c|c|c|c|c|c|c|c|c|c|c|c|c|c|c|c|}
\hline & M1 & M2 & M3 & M4 & M5 & M6 & M7 & P1 & $\mathrm{P} 2$ & P3 & $\mathrm{P} 4$ & P5 & P6 & P7 & P8 & P9 \\
\hline Sex ratio $(\%)$ & 97.67 & 97.68 & 99.56 & 102.10 & 99.02 & 101.07 & 108.15 & 102.34 & 102.15 & 102.01 & 103.95 & 97.58 & 97.58 & 100.53 & 103.06 & 100.44 \\
\hline Population density $\left(\mathrm{km}^{2}, \ln \right)$ & 9.72 & 8.42 & 7.94 & 7.89 & 7.99 & 7.94 & 6.95 & 7.04 & 4.49 & 5.33 & 5.48 & 5.41 & 4.99 & 4.94 & 5.72 & 5.72 \\
\hline Aging index & 68.87 & 84.87 & 64.99 & 52.59 & 49.91 & 50.64 & 38.58 & 49.05 & 98.23 & 83.33 & 93.98 & 100.53 & 126.69 & 110.15 & 72.70 & 74.60 \\
\hline Population inflow (thousands) & -82.55 & -26.58 & -15.23 & 14.18 & -2.05 & -3.02 & 0.22 & 103.87 & -0.75 & 3.43 & 11.93 & -7.41 & -9.21 & -5.35 & 5.37 & 5.69 \\
\hline Relative poverty rate (\%) & 0.22 & 0.27 & 0.27 & 0.20 & 0.19 & 0.28 & 0.11 & 0.18 & 0.32 & 0.29 & 0.33 & 0.34 & 0.32 & 0.33 & 0.24 & 0.34 \\
\hline GRDP per capita (million Won, ln) & 3.34 & 2.89 & 2.75 & 3.05 & 2.85 & 2.88 & 3.96 & 3.10 & 3.02 & 3.22 & 3.65 & 2.99 & 3.43 & 3.37 & 3.27 & 3.10 \\
\hline Employment rate of those aged 15-64 (\%) & 64.37 & 60.97 & 62.56 & 64.15 & 61.05 & 62.07 & 61.59 & 64.35 & 62.77 & 64.68 & 67.15 & 62.89 & 67.20 & 66.98 & 64.41 & 70.41 \\
\hline Social welfare expenditure, in \% general accounts & 27.40 & 32.25 & 32.57 & 27.96 & 35.08 & 32.54 & 23.10 & 23.18 & 17.63 & 21.53 & 19.34 & 22.75 & 18.41 & 19.27 & 20.42 & 14.23 \\
\hline Divorce rate of females (\%o) & 5.10 & 5.16 & 4.90 & 6.73 & 5.25 & 5.32 & 5.59 & 6.12 & 5.25 & 5.24 & 5.09 & 4.75 & 4.22 & 4.31 & 5.16 & 5.69 \\
\hline$\%$ of married foreign women in Korea $(\%)$ & 6.65 & 6.19 & 5.92 & 7.55 & 6.26 & 6.25 & 6.23 & 7.19 & 8.03 & 8.51 & 9.23 & 10.62 & 11.80 & 8.38 & 7.58 & 8.65 \\
\hline Number of crimes per thousand & 35.70 & 38.19 & 38.66 & 34.96 & 43.42 & 32.98 & 36.38 & 33.83 & 38.25 & 35.57 & 34.03 & 31.85 & 35.14 & 35.56 & 36.43 & 47.61 \\
\hline One-person household rate (\%) & 24.54 & 23.12 & 22.03 & 20.63 & 23.63 & 24.99 & 20.79 & 20.26 & 27.60 & 26.27 & 26.37 & 26.01 & 27.98 & 27.85 & 24.67 & 25.09 \\
\hline Number of psychiatrists per 100,000 & 51.16 & 48.11 & 39.07 & 26.93 & 39.73 & 42.76 & 24.91 & 33.67 & 39.05 & 40.69 & 38.29 & 39.32 & 38.85 & 41.98 & 40.87 & 33.03 \\
\hline
\end{tabular}

M: metropolitan city, P: province 